\title{
LEGISLATIVE REGULATION OF THE GRAIN MARKET IN THE REPUBLIC OF KAZAKHSTAN
}

\section{ЗАКОНОДАТЕЛЬНОЕ РЕГУЛИРОВАНИЕ РЫНКА ЗЕРНА В РЕСПУБЛИКЕ КАЗАХСТАН}

\author{
Iskakov S.M., Master of Economics, Senior Economic Expert \\ Искаков С.М., магистр экономики, старший эксперт-экономист \\ Economic Research Institute, Astana, Republic of Kazakhstan \\ Институт экономических исследований, Астана, Республика Казахстан \\ E-mail: s.iskakov@gmail.com, Phone: +7(705) 423-15-30
}

\begin{abstract}
Kazakh grain is one of the competitive on world commodity markets; therefore the state regulation of production and turnover of Kazakh grain is directly correlated with the overall competitiveness of country. The aim of this research is to identify the main vectors, as well as state control forms of the regulatory impact on the grain market. In addition, on the basis of the research, recommendations for improving the grain market in Kazakhstan will be provided.

\section{АННОТАЦИЯ}

Казахстанское зерно является одним из конкурентоспособных на мировых товарных рынках, а государственное регулирование производства и оборота казахстанского зерна напрямую взаимосвязано с конкурентоспособностью страны. Целью данной научной работы является определение основных векторов, а также форм влияния регуляторного воздействия государства на рынок зерна. Кроме того, на основе проведенных исследований будут даны рекомендации по совершенствованию данного рынка.
\end{abstract}

\section{KEY WORDS}

Grain market; Government regulation; Economic mechanism; Global market; Kazakhstan.

\section{КЛЮЧЕВЫЕ СЛОВА}

Зерновой рынок; Государственное регулирование; Экономический механизм; Мировой рынок; Казахстан.

Казахстанское зерно является одним из наиболее конкурентоспособных не только на рынках ЕЭП и СНГ, но и на мировых рынках зерна.

Республика Казахстан обладает сравнительными преимуществами в торговле пшеницей (мукой). В 2011-2012 маркетинговом году доля Казахстана в мировом экспорте пшеницы и муки возросла до 6,8\%, что говорит о ведущей роли Республики Казахстан в мировом производстве зерна. Таким образом, вопрос необходимости регулирования рынка зерна Казахстана, как одного из стратегических для нашей страны, является оправданным.

В настоящее время государственное регулирование рынка зерна осуществляется в рамках Закона Республики Казахстан «О зерне» от 19 января 2001 года № 143-ІІ. Кроме того, 18 апреля 2012 года вышел приказ Министра сельского хозяйства Республики Казахстан «Об утверждении форм предписания об устранении нарушения требований законодательства Республики Казахстан о зерне, протокола об административном правонарушении, постановления по делу об административном правонарушении» от 18 апреля 2012 года № 18-03/179. Целью данного Приказа являлась регламентация процесса наложения административной ответственности за нарушения в области торговли и хранения зерна. 
Далее дана попытка оценить влияние государственного регулирования рынка зерна в Республике Казахстан.

\section{АНАЛИЗ ТЕКУЩЕГО СОСТОЯНИЯ}

Состояние мирового рынка зерна. В 2011 году, согласно оценке Министерства сельского хозяйства США, мировой урожай зерновых составил 2,295 миллиарда тонн. Однако потребление зерна в 2011 году выросло на 90 млн. тонн, составив 2,28 млрд. тонн. На протяжении последних 12 лет переходящие запасы зерна остаются на достаточно низком уровне, что обусловливает рост цен на продовольствие.

В мире доминируют три зерновых культуры: пшеница и рис, которые в основном идут непосредственно в пищу, а также кукуруза, которая в большей части используется в качестве корма для скота. Несмотря на падение урожая кукурузы из-за высоких летних температур в США, лидера по производству, мировое производство этой культуры в 2011 году составило 868 млн. тонн, что является историческим рекордом. Урожай пшеницы составил 689 млн. тонн, риса - 461 млн. тонн.

На сегодняшний день странами, производящими около половины объема мирового зерна являются Китай, США и Индия. Так, в 2011 году Китаем было собрано 456 млн. тонн зерна, Соединенными Штатами - 384 млн. тонн, Индией - 226 млн. тонн.

Проблемой для мировой продовольственной безопасности является то, что дальнейший рост урожайности крайне затруднителен, поскольку зерновыми культурами с высокой урожайностью засеяны большинство площадей в мире, за исключением Африки южнее Сахары. Во всем мире зерновые выращиваются на площади в 700 млн. га., т.е. при учете населении в 7 млрд. человек, на каждого приходится по 0,1 га посевов зерновых, что вдвое меньше, чем в начале 1960-х. Кроме того, сельское хозяйство активно применяет удобрения и орошение. Мировые урожаи зерна увеличивались в среднем на 2,2\% в год в период с 1970 по 1990 гг. Однако, в период между 1990 и 2010г., годовой рост составлял только половину этой величины.

Таким образом, многие страны вынуждены закупать импортное зерно. На фоне замедления роста урожайности и сокращения площадей под зерновые, наблюдается волатильность цен на продукты питания. Япония продолжает оставаться крупнейшим импортером зерна в мире - в 2011 году она приобрела более 25 млн. тонн зерна зарубежом, большая часть, которой пошла на корм для животных. Египет, Мексика, Южная Корея и Саудовская Аравия в 2011 г. импортировали более 10 млн. тонн зерна каждая. Более всего зависимы от импорта засушливые страны Ближнего Востока. Например, Саудовская Аравия в настоящее время зависит от импорта на 90\%. [0]

Рост потребления в Китае создает потенциал для импорта еще большего количества зерна в последующие годы. Поскольку благосостояние в Китае растет, соответственно растет потребление мяса, молока, яиц. В связи с этим резко возросло потребление зерна на корм в стране, впервые превысив потребление в США в 2010 году (там его использование падает) . Китай, в настоящее время, является мировым лидером по количеству зерна, которое идет на нужды животноводства, с показателем в 149 млн. тонн.

В начале июля 2012 года Министерство сельского хозяйства США опубликовало очередной прогноз, согласно которому мировой урожай зерновых в сезоне 2012-2013 годов снизится. В число стран, по которым снижены прогнозы сбора зерна, также попали Казахстан и Россия. По данным Министерства сельского хозяйства США мировой урожай зерновых в этом сезоне составит 2,31 млрд. тонн, а не 2,37 млрд. тонн, как планировалось в июне. Прогноз мирового производства пшеницы скорректирован с уменьшением на семь миллионов тонн и составляет 665 млн. тонн.

Основной причиной понижения прогнозных оценок по 2012 году стала засуха в Причерноморском регионе, распространяющаяся дальше на восток России. В России, по прогнозу, будет собрано 49 миллионов тонн пшеницы, на четыре миллиона меньше, чем рассчитывали в июне. Засушливая погода в Казахстане послужила причиной 
снижения прогноза и по Казахстану: с 15 млн. тонн до 13 млн. тонн. При этом экспорт прогнозируется на уровне 7 млн. тонн. [0]

Текущее состояние рынка зерна в Казахстане. На сегодняшний день основу сельскохозяйственного производства составляют зерновые культуры. В 2011 году было выпущено продукции (услуг) сельского хозяйства на сумму 2286 млрд. тенге, из них $58,5 \%$ приходилось на продукцию растениеводства. В растениеводстве очевидно преобладание зерновых культур: по валовому сбору, по посевной площади.

Таблица 1 - Валовой сбор и посевная площадь основных сельскохозяйственных культур (2011 г.)

\begin{tabular}{|c|c|c|c|c|c|c|}
\hline$\Pi / п$ & $\begin{array}{c}\text { Зерновые } \\
\text { (включая рис) и } \\
\text { бобовые культуры } \\
\text { (в весе после } \\
\text { доработки) }\end{array}$ & $\begin{array}{c}\text { Масличные } \\
\text { культуры }\end{array}$ & Картофель & $\begin{array}{c}\text { Овощи } \\
\text { открытого и } \\
\text { закрытого } \\
\text { грунта }\end{array}$ & Хлопчатник & $\begin{array}{c}\text { Сахарная } \\
\text { свекла }\end{array}$ \\
\hline $\begin{array}{c}\text { Валовой } \\
\text { сбор, тыс. } \\
\text { тонн }\end{array}$ & 26960,5 & 1141,9 & 3076,1 & 2877,7 & 336,0 & 200,4 \\
\hline $\begin{array}{l}\text { Посевная } \\
\text { площадь, } \\
\text { тыс. гектар }\end{array}$ & 16219,4 & 1816,2 & 184,4 & 128,7 & 160,6 & 18,2 \\
\hline
\end{tabular}

Примечание: составлено на основе данных Агентства Республики Казахстан по статистике.

Среднегодовая урожайность зерновых культур за последние 5 лет (2007-2011 гг.) в Казахстане составила 12,2 ц/га против 10,6 - показателя предыдущих 5 лет и возросла на 1,6 ц/га (15\%). За последние 5 лет (2007-2011 гг.) на поддержку отрасли растениеводства направлено 123,9 млрд. тенге бюджетных средств, что в 5,8 раз больше уровня предыдущих 5 лет (2002-2006 гг.). Ежегодно выделяются кредитные ресурсы на проведение весенне-полевых и уборочных работ. В 2011 году зерновые культуры с применением влагоресурсосберегающих технологий возделывались на площади 11,7 млн. га, что в 3,2 больше уровня 2006 года. Объемы внедрения капельного орошения составили 21 тыс. га, что в 29 раз превышает показатель 2007 года.

Основным показателем, который влияет на рынок зерна, является валовый урожай, который в свою очередь характеризуется нестабильностью и колеблется в зависимости от погодных условий от 12,2 млн. тонн (в 2010 году) до 22-23 млн. тонн (в 2011 году). Цены на зерно меняются обратно пропорционально валовому урожаю.

Нестабильность зернового рынка влечет неустойчивое финансовое положение сельхозтоваропроизводителей (СХТП), что сказывается на объеме инвестиций в современные технологии в растениеводстве.

Такая нестабильность несет в себе угрозу продовольственной безопасности. В долгосрочной перспективе она может не позволить Казахстану закрепиться на мировом рынке зерна, поскольку зерновики могут несколько лет налаживать деловые контакты на определенных рынках, и потерять их в один неурожайный год.

Определенные проблемы возникают и у экспортеров в части реализации пшеницы на мировых рынках. Потребление на традиционных рынках, а это Средняя Азия, Афрганистан, Иран, составляет порядка $6 \mathrm{mлн.} \mathrm{тонн} \mathrm{вне} \mathrm{зависимости} \mathrm{от} \mathrm{цен.}$ Собственное потребление составляет около 8 млн. тонн.

Таким образом, в годы, когда объем урожая превышает собственное потребление плюс экспорт на традиционные рынки, у СХТП возникают проблемы с реализацией зерна на альтернативных рынках. По причине отдаленности от мировых рынков достаточно велики транспортные расходы, в силу которых снижается цена и доходность для СХТП.

В связи с этим в растениеводстве требуется диверсификация производства. Наше производство должно ориентироваться на рынок, на котором имеется значительный спрос на масличные, бобовые, кормовые и т.д. В перспективе посевные площади должны быть приведены в соответствие со спросом и рыночной 
конъюнктурой. Большие перспективы нам в этом дает животноводство, которое должно в будущем стать стабильным потребителем продукции растениеводства.

Также необходимо отметить, что цены на сельхозпродукцию за последние 6 лет практически не меняются. Средняя цена колеблется в пределах 150-200 у.е. за тонну. В то же время стоимость ГСМ с 2005 года выросла в 2,8 раза (для СХТП), а стоимость гербицидов и удобрений - в 2-3 раза. Низкими темпами идет обновление сельскохозяйственной техники, которая имеет износ в пределах $87 \%$ и требует повышенных затрат на поддержание в работоспособном состоянии [0].

Одной из основных задач Государственной программы по форсированному индустриально-инновационному развитию Республики Казахстан на 2010-2014 годы является обеспечение конкурентоспособного производства сельскохозяйственной продукции в объемах, достаточных для покрытия потребностей внутреннего рынка и формирования экспортных ресурсов, с целью занятия ведущих позиций на внешних рынках. Ожидается, что в 2015 году экспортный потенциал отрасли в общем объеме экспорта страны увеличится до 8\%. Достижение поставленных целей будет возможно за счет институциональных преобразований, таких как нормативно-правовое регулирование и, в частности, изменение и дополнение новых норм в правовую базу зернового рынка с целью разрешения возникающих проблем.

\section{ЭКОНОМИЧЕСКОЕ И ИНСТИТУЦИОНАЛЬНОЕ СОВЕРШЕНСТВОВАНИЕ ФУНКЦИОНИРОВАНИЯ ЗЕРНОВОГО РЫНКА РЕСПУБЛИКИ КАЗАХСТАН}

В настоящее время среди различных направлений развития рынка зерна Республики Казахстан можно выделить ключевые, которые могут быть отражены в части:

- определения условий страхования гражданско-правовой ответственности хлебоприемных предприятий перед держателями зерновых расписок и ее частей;

- введения системы электронных зерновых расписок;

- формирования механизма и использования государственных ресурсов зерна, в том числе в целях обеспечения потребности отрасли животноводства и птицеводства в фуражном зерне.

Определение условий страхования гражданско-правовой ответственности хлебоприемных предприятий. В сельскохозяйственной отрасли условия хранения зерна должны соответствовать различным критериям. Очень важно сохранить качественные показатели зерна, так как от его потребительских свойств будет во многом зависеть закупочная цена. В сельском хозяйстве в качестве хранилищ для зерна используются элеваторы - специализированные высокомеханизированные сооружения для хранения больших партий зерна и доведения его до кондиционного состояния без потери фризиологических и фризико-химических свойств. К сожалению, возраст большинства казахстанских ХПП превышает 40-50 лет. На этих предприятиях применяется изношенное, устаревшее оборудование. С целью защиты имущественных интересов владельцев зерна действующим законодательством предусмотрено фуунционирование гарантирования исполнения обязательств по зерновым распискам (АО «КазАгроГарант»).

Однако на сегодняшний день не все ХПП участвуют в системе гарантирования исполнения обязательств по зерновым распискам. Это создает риски для держателей зерновых расписок. Поэтому в целях защиты имущественных интересов СХТП необходимо регламентировать процесс обязательного страхования ХПП своей гражданско-правовой ответственности перед держателями зерновых расписок (держателями электронных зерновых расписок)

Целью страхования гражданско-правовой ответственности ХПП перед держателями зерновых расписок является обеспечение защиты имущественных интересов держателей зерновых расписок (держателей электронных зерновых расписок), и залоговых свидетельств, которым причинен вред в результате 
осуществления хлебоприемными предприятиями своей деятельности, посредством осуществления страховых выплат.

Страхование гражданско-правовой ответственности хлебоприемных предприятий перед держателями зерновых расписок и их частей (держателями электронных зерновых расписок), осуществляется на основании договора, заключаемого между страхователем и страховщиком. При этом, размер страховой премии, а также порядок и сроки ее уплаты, устанавливаются по соглашению сторон. Размер страховой суммы по договору страхования гражданско-правовой ответственности хлебоприемного предприятия перед держателями зерновых расписок (держателями электронных зерновых расписок), определяется путем умножения максимальной стоимости зерна сельскохозяйственных культур на техническую емкость зернохранилища и не может быть менее суммы кратной 100000 месячных расчетных показателей.

Определение условий страхования гражданско-правовой ответственности хлебоприемных предприятий перед держателями зерновых расписок, повлияет в первую очередь, на показатели социального благосостояния.

Введение страхования гражданско-правовой ответственности позволяет защитить права и имущественные интересы держателей зерновых расписок в случае наступления страховых случаев, т.е. при утрате или ухудшении качества зерна вложенные в ХПП деньги могут быть возвращены держателям расписок. Таким образом, данная норма направлена на повышение дохода вкладчиков - держателей зерновых расписок.

Однако, с другой стороны, отрицательным последствием введения обязательного страхования может быть повышение тарифов на страхование, и затем возможное увеличение стоимости зерна. Возможный рост цены зерна приведет к росту цен на хлебобулочные изделия. Данный процесс в случае его реализации окажет отрицательное воздействие на социальное положение малоимущих слоев населения, чей доход ниже прожиточного минимума и в потребительской корзине которых изменение стоимости хлеба и мукомольных изделий может быть ощутимым эфффектом.

Кроме того, страхование гражданско-правовой ответственности ХПП перед держателями зерновых расписок приведет к росту издержек ХПП в связи с уплатой страховых премий. По данным Министерства сельского хозяйства Республики Казахстан (далее - МСХ РК), общая емкость лицензированных ХПП составила 13 942,8 тыс. тонн, средняя стоимость пшеницы мягкой 3 класса по данным АО «Казагромаркетинг» составила 33981 тенге за тонну. Таким образом, в среднем страховая сумма ХПП может составить 473,8 млрд. тенге. Как было уже отмечено, размер страховой премии, а также порядок и сроки ее уплаты, устанавливаются по соглашению сторон. К примеру, если страховой тариф составит $0,4 \%$ от страховой суммы, тогда расходы ХПП на страхование данного вида ответственности составят 1,9 млрд. тенге.

Введение системы электронных зерновых расписок. Следующим направлением совершенствования нормативно-правовой базы рынка зерна является введение системы электронных зерновых расписок (далее - СЭЗР). Электронная зерновая расписка - это бездокументарная неэмиссионная ценная бумага, регистрируемая хлебоприемным предприятием в подтверждение принятия зерна от владельца зерна на хранение в бездокументарной форме (в виде совокупности электронных записей в государственном реестре).

Система электронных расписок успешно применяется в ряде развитых и развивающихся стран. Успешным примером введения системы электронных расписок является США, где данная система первоначально была введена в хлопковой индустрии. Переход США на СЭЗР был осуществлен в 2011 году с поправками в Закон о складировании и хранении США (United States Warehouse Act). Приложение 1 WA460-2 к Закону о складировании и хранении США регламентирует предоставление ХПП информации об электронных зерновых расписках, форму и содержание электронных 
зерновых расписок, а также порядок перевода бумажных зерновых расписок в электронные.

Внедрение СЭЗР призвано стимулировать развитие биржевой индустрии, послужит системообразующим средством для саморегулирования рынка зерна, повысит его прозрачность, сократит цепь торговых посредников и, в конечном итоге, может послужить установлению реальной цены на зерно, что также окажет положительное влияние на уровень инфляции. По мнению отечественных экспертов зернового рынка, низкая эффективность функционирования отечественного рынка зерна обусловлена многими объективными и субъективными причинами. Среди них немаловажное значение имеет, отсутствие или неразвитость необходимых важных элементов инфраструктуры рынка зерна, существующих в развитых странах зерновых державах, в том числе, биржевой торговли зерном.

Введение и регламентация работы электронных зерновых расписок, а также порядка их обращения, будут способствовать повышению прозрачности обращения зерна и снижению рисков мошенничества, что повысит инвестиционную привлекательность зернового рынка не только для отечественных, но также и международных фринансовых институтов. За период 2002-2010 годы по данным мониторинга обращения зерновых расписок по зерновым распискам сельхозтоваропроизводителями республики получены кредиты банков второго уровня на сумму 429,5 млрд. тенге (3,0 млрд. долларов США).

Введение СЭЗР также предусматривает автоматизацию процесса регистрации зерновой расписки на всех ХПП, процесса регистрации лабораторных данных, проведение мониторинга бланков строгой отчетности, вывод информации о зерновой расписке на печать, а также проведение индоссамента в режиме онлайн без фризического присутствия покупателя/продавца посредством подтверждения совершенного индоссамента в СЭЗР. Данные нормы могут сократить и устранить факты недостачи давальческого зерна, выписки зерновой расписки на несуществующий объем зерна, фракты подделки зерновой расписки. Так, по информации Комитета государственной инспекции в АПК МСХ РК в 2008-2010 годах необеспеченных зерновых расписок было выписано на объем 55546 тонн, недостача составила 180750 тонн, т.е. общий ущерб, причиненный субъектам АПК, составил 7 млрд. тенге (55 546+180 750*30 000 (200 долларов США), что соответствует 0,013\% ВВП за данный период. Также вышеуказанные нормы могут положительно сказаться на решении вопроса рационального распределения зерна, что обеспечит оптимальную загруженность ХПП.

Таблица 2 - Наличие зерна на лицензированных ХПП республики по состоянию на 01.01.2012 г.

\begin{tabular}{|c|c|c|c|c|c|c|}
\hline$\Pi / \Pi$ & $\begin{array}{c}\text { Количество } \\
\text { ХПП, ед. }\end{array}$ & $\begin{array}{l}\text { Общая } \\
\text { емкость, } \\
\text { тыс. тонн }\end{array}$ & $\begin{array}{c}\text { Всего } \\
\text { зерна, } \\
\text { тыс. тонн }\end{array}$ & $\begin{array}{c}\text { Загруженность } \\
\text { ХПП, \% }\end{array}$ & $\begin{array}{l}\text { Доля } \\
\text { зерна } \\
\text { ХПП в } \\
\text { ВВП, \% }\end{array}$ & $\begin{array}{c}\text { Доля } \\
\text { нереализованной } \\
\text { емкости в ВВП, \% }\end{array}$ \\
\hline $\begin{array}{c}\text { Всего по } \\
\text { республике }\end{array}$ & 221 & 13936,9 & 10535,2 & 75,6 & 0,85 & 0,27 \\
\hline
\end{tabular}

Примечание: составлена на основе данных Агентства Республики Казахстан по статистике и Министерства сельского хозяйства Республики Казахстан.

Как видно из таблицы 2, средняя загруженность 221 ХПП на 75,6\% может оцениваться как $0,85 \%$ ВВП при средних ценах на пшеницу за 2011 год. Нереализованная емкость ХПП соответствует приблизительно 0,27\% ВВП.

Эфрфективное функционирование рынка зерна посредством введения электронных зерновых расписок также может положительно повлиять на стабилизацию цен на рынке зерна и продуктов, производимых из зерна. Постоянство уровня цен хлеба, хлебобулочных изделий и других продуктов способствует экономии доходов населения, особенно доходов малоимущих слоев населения.

Кроме положительных последствий введения СЭЗР, данная норма является расходной для государственного бюджета, на которую, согласно данным МСX РК, 
потребуется 19147668 тенге, из них на обучение пользователей работе СЭЗР - 8937 900 тенге, на ежегодное техническое и технологическое обслуживания государственного реестра - 10209768 тенге.

Однако, как указывалось ранее, введение СЭЗР будет способствовать снижению рисков, неопределенности и повышению прозрачности рынка зерна, что также позволит сократить потери государственного бюджета по недостачи зерна в государственных ХПП, а также, косвенно, увеличить доходы государственного бюджета за счет положительного влияния данной нормы на повышение его инвестиционной привлекательности для международных организаций и финансовых институтов, и, как результат, повышении налогооблагаемой базы сельхозпроизводителей.

Обеспечение потребности отрасли животноводства и птицеводства в фруражном зерне. Кроме перечисленных выше двух основных направлений ключевой тенденцией в государственном регулировании с целью развития зернового рынка можно выделить уточнение одной из целей государственного управления и регулирования рынка зерна - устранение возможного дефицита фуражного зерна (кормов) в животноводстве и птицеводстве за счет реализации государственных стабилизационных ресурсов зерна СХТП, занимающимся разведением сельскохозяйственных животных и птиц в целях обеспечения потребности в фуражном зерне, а также их кредитование для реализации данной цели.

Вопрос необходимости государственного регулирования отечественного рынка мяса с помощью регулирования рынка фруражного зерна неоднократно отмечался казахстанскими экспертами. В частности, рынок мяса птицы нуждается в эфффективной системе государственной защиты от импорта и поддержки, особенно в условиях демпинга цен и значительного давления со стороны поставщиков услуг и кормового зерна.

Уровень поголовья птицы в стране имеет сильную зависимость от валового сбора зерна и цен на фруражное зерно, поэтому государственное регулирование рынка кормового зерна, как приоритетное условие, благотворно отразится на производстве мяса птицы в частных и фермерских хозяйствах. Это, в свою очередь, может оказать положительное воздействие на сдерживание уровня цен на мясо и мясные изделия. Сейчас в Казахстане наблюдается значительный уровень импортозависимости по продуктам переработки: колбасные изделия, примерно, на 40\%, консервы мясные и мясорастительные - на $52 \%$.

В соответствии с данными Агентства Республики Казахстан по статистике на конец 2011 года поголовье скота и птицы составило:

- КРС - 5 702,4 тыс. голов (для сравнения 1991 год - 9 592,4 тыс. голов);

- овцы и козы - 18 091,9 тыс. голов (1991 год - 34 555,7 тыс. голов);

- свиньи - 1204,2 тыс. голов (1991 год - 2 976,1тыс. голов);

- лошади - 1 607,4 тыс. голов (1991 год - 1666,4 тыс. голов);

- верблюды - 173,2 тыс. голов (1991 год - 145,1 тыс. голов);

- птица - 32,9 млн. голов (1991 год - 59,9 млн. голов).

За 2011 год из Республики Казахстан было экспортировано:

- живых животных на 2,4 млн. долл. США (в страны ТС - 2,1 млн. долларов США);

- мяса и пищевых мясных субпродуктов на $3,1 \mathrm{mлн.} \mathrm{долл.} \mathrm{США} \mathrm{(в} \mathrm{страны}$ ТС - 0,6 млн. долларов США);

- молочной продукции, яиц и меда на 4,1 (в страны ТС - 1,9 млн. долларов США).

Для сравнения в 2011 году только продукции мукомольно-крупяной промышленности экспортировано на сумму около 600 млн. долларов США. Очевидно значительное отставание животноводческого сектора от растениеводства.

В виду данных обстоятельств, введение норм государственного регулирования предусматривающих обеспечение потребности отрасли животноводства и птицеводства в фуражном зерне на территории Республики Казахстан являются весьма оправданными. В 2011-2012 годы, согласно данным МСХ РК, обеспеченность в фруражном зерне, по сравнению с 2007-2008 годами, ухудшилась и составила: 
- по грубому корму - 93\% (105,5\% в 2007-2008гг.);

- по силосу - 19,9\% (36,4\% в 2007-2008гг.);

- по грубому и сочному корму - 90,8\% (101,8\% в 2007-2008гг.).

За 2011 год согласно данным Агентства Республики Казахстан по статистике чистый экспорт составил 22,3\% ВВП. По данным Комитета таможенного контроля Министерства фринансов Республики Казахстан за 2011 год всего было экспортировано зерновых культур на сумму 728,6 млн. долларов США, что составляет 1,8\% от чистого экспорта, или $0,4 \%$ от ВВП.

Однако существует взаимосвязь между ростом экспорта зерна и падением производства в животноводческой отрасли, которую подтверждает специалист службы сельскохозяйственного маркетинга при министерстве сельского хозяйства США Билл Мейерс в своем исследовании «Перспективы развития рынка зерна в мире и в странах СНГ». По его мнению, быстрый прирост экспорта зерна в Казахстане случился «благодаря резкому сокращению животноводческого сектора в девяностые годы». Если бывший Советский Союз производил продукты животноводства с высокой себестоимостью, используя импортируемые кормовое зерно и масличные культуры, то страны, ставшие независимыми и ориентированные на рыночную экономику, сами стали крупными импортерами мяса и другой животноводческой продукции. Значительное падение спроса на местные корма не только положило конец импорту зерна и масличных, но и создало условия для экспорта излишков зерна.

Вместе с тем увеличение закупа зерна государственных реализационных ресурсов зерна (далее - ГРРЗ) с целью регулирования внутреннего рынка потребует дополнительных фринансовых затрат из республиканского бюджета. С этой целью, согласно расчетам, придется увеличить зерновые резервы AO «НК «Продовольственная контрактная корпорация», являющегося агентом по управлению государственными ресурсами зерна (далее - агент), до уровня 58480 млн. тенге (при максимальной закупочной цене агента - 21000 тенге за тонну). Однако согласно отдельному фринансовому отчету агента за 2011 год доходы от реализации зерна по МСФО составили 58062 млн. тенге, себестоимость же реализованного зерна составила 51006 млн. тенге. В 2011 году им было закуплено зерна в объеме 8 млн. тонн: $5 \mathrm{mлн.} \mathrm{тонн} \mathrm{в} \mathrm{начале} \mathrm{августа} \mathrm{и} 3 \mathrm{mлн.} \mathrm{тонн} \mathrm{в} \mathrm{течение} \mathrm{осени.} \mathrm{Исходя} \mathrm{из}$ представленных данных, закуп зерна на увеличение ГРРЗ может быть реализован в рамках имеющихся ресурсов агента и реализация данного направления, не отразится на расходах государственного бюджета.

Меры, предусматривающие, в случае необходимости, возмещение расходов агента по хранению, транспортировке и реализации зерна государственных ресурсов, использование средств денежного резерва агента на погашение обязательств перед республиканским бюджетом предоставляют более гибкие условия для агента, а также республиканского бюджета в части перераспределения денежных средств. В 2011 году, согласно консолидированной финансовой отчетности агента, совокупный доход, за вычетом всех налогов и обязательных платежей, по МСФО составил 760392 тыс. тенге, что говорит о наличии минимальной вероятности возмещения реализации данной статьи расходов за счет республиканского бюджета.

Повышение прозрачности и достоверность информации будет способствовать снижению информационной асимметрии и снижению барьеров ведения предпринимательской деятельности на рынке зерна, что положительно отразится на инвестиционной активности. Кроме того, повышение прозрачности рынка зерна положительно повлияет на сокращение ненаблюдаемой экономики в сельском хозяйстве и фрормализацию оптово-розничной торговли в данном секторе экономики.

\section{ЗАКЛЮЧЕНИЕ}

Международные эксперты высоко оценивают казахстанский рынок зерна, который остается одним из наиболее конкурентоспособных не только на уровне постсоветских интеграционных объединений (Таможенный союз и Единое экономическое 
пространство), но также и на мировых товарных рынках. Такие широко используемые инструменты, применяемые в данной отрасли (как например, зерновые расписки) только начинают внедряться в странах Таможенного союза (например, Российская Федерация). При этом, необходимо также стимулировать и повышать прозрачность данного рынка с целью привлечения еще больших инвестиций, а также обеспечения безопасности путем сокращения вероятности мошенничества и преступлений в данной отрасли, создавать правовую основу для внедрения инновационных подходов. Роль передовой страны в области производства зерна и регулирования его рынка оставляет небольшое поле для бенчмаркинга - с целью развития данной отрасли, нашей стране приходится ориентироваться на очень узкий круг стран, такие как США и Китай. При этом, основные проблемы зерновой отрасли Казахстана больше связаны с неразрешенностью других вопросов, как например, зависимость от погодных условий в виду отсутствия влагосберегающих технологий, низкая урожайность с 1 га. и т.д. Исходя из вышеизложенного, можно сделать вывод о том, что казахстанский рынок зерна достаточно эфффективно регулируется государством, однако низкий уровень внедрения технологий в данной отрасли делает данный рынок более волатильным и менее привлекательным для инвестиций, что может снизить конкурентоспособность зерновой отрасли Казахстана. Таким образом, казахстанскому зерновому рынку необходимы инструменты государственного регулирования, направленные на разрешение вопросов его технологической модернизации, повышения урожайности, а также проработки всех процессов данного рынка - от сбора зерна до конечной реализации (на внутреннем рынке или в виде экспорта) или переработки.

В настоящее время с целью развития зернового рынка Республики Казахстан, выделяют меры, предусматривающие определение условий страхования гражданскоправовой ответственности ХПП перед держателями зерновых расписок, введение системы электронных зерновых расписок, обеспечение потребности отрасли животноводства и птицеводства в фуражном зерне.

Дальнейшее внедрение и реализация данных направлений позволит обеспечить эффективное ффункционирование всей системы соответствующих законодательных, подзаконных актов и отраслевых нормативных правовых актов. Эта система, основываясь на принципах и положениях Конституции Республики Казахстан и едином терминологическом подходе, будет способствовать обеспечению защиты интересов держателей зерновых расписок и ее частей и совершенствованию механизма фрормирования и использования государственных ресурсов зерна.

\section{БИБЛИОГРАФИЯ}

[1] Закон Республики Казахстан «О зерне» от 19 января 2001 года №143.

[2] Проект закона Республики Казахстан «О внесении изменений и дополнений в некоторые законодательные акты Республики Казахстан по вопросам регулирования зернового рынка», 2012.

[3] Grain: World Markets and Trade, July 2012, United States Department of Agriculture, www.usda.gov.

[4] Тенденции. Мировой рынок зерна-2011 в цифрах. Агентство АгроФакт, http://agronews.ru/news/detail/116866/

[5] О новых фрормах государственной поддержки в сфрере растениеводства. Министерство сельского хозяйства Республики Казахстан, http://www.minagri.kz/images/pokazateli/zemledelie/13102011.rar

[6] Официальный сайт Министерства сельского хозяйства Республики Казахстан, www.minagri.kz

[7] Официальный сайт Агентства Республики Казахстан по статистике, www.stat.kz. 